\title{
Low plant diversity and floristic homogenization in fast-urbanizing towns in Shandong Peninsular, China: Effects of urban greening at regional scale for ecological engineering
}

\author{
Guang-mei Wang ${ }^{\mathrm{a}}$, Jin-cheng Zuo ${ }^{\mathrm{b}}$, Xue-Rong $\mathrm{Li}^{\mathrm{a}}$, Yu-hong Liu ${ }^{\mathrm{a}}$, Jun-bao Yu ${ }^{\mathrm{a}, *}$, \\ Hong-bo Shao ${ }^{\mathrm{a}, \mathrm{c}, *}$, Yun-zhao $\mathrm{Li}^{\mathrm{a}}{ }^{\mathrm{d}}$ \\ ${ }^{a}$ Key Laboratory of Coastal Environmental Processes and Ecological Remediation, Yantai Institute of Coastal Zone Research, Chinese Academy of Sciences, \\ Yantai, Shandong 264003, PR China \\ b College of Life Sciences, Ludong University, Yantai, Shandong 264025, PR China \\ ' Institute for Life Sciences, Qingdao University of Science E' Technology(QUST), Qingdao 266042, PR China \\ d Graduate School of Chinese Academy of Science, Beijing 100049, PR China
}

\section{A R T I C L E I N F O}

\section{Article history:}

Received 19 November 2013

Received in revised form

19 December 2013

Accepted 24 December 2013

Available online 31 January 2014

\section{Keywords:}

Urban ecological greening

Plant diversity

Floristic homogenization

Exotic species

Richness difference

Species replacement

\begin{abstract}
A B S T R A C T
Urban forest construction is believed as an effective method to preserve urban biodiversity and restore urban green ecosystem. However, in some fast-urbanizing towns, the most urban flora in the built-up area was almost totally manmade, where is new expanded areas mainly transformed from cultivated lands. How such urban flora contribute to local and regional diversity is seldom quantitatively tested. In this study, we conducted a comprehensive investigation of man-made urban flora in 15 fast-urbanizing towns in Shandong Peninsular, China, to explore the effect of urban greening on the local and regional plant diversity. The results that showed huge investment to urban greening contribute to high urban green coverage but do not foster high plant diversity. Exotic species has lower overall dissimilarity between town pairs than native in either cultivated or wild flora. Urban greening does not result in high proportion of exotic species, however, either wild flora or cultivated flora show homogenizing tendency due to the expansion of exotic species. Nevertheless, the main driving forces are different: the wild flora are homogenized by diminished species richness difference while the cultivated flora due to the decreased species replacement. We therefore suggest biodiversity conservation should be more considered and strengthened in further urban greening. Our study could also provide useful reference data in biotic homogenization research in China.
\end{abstract}

(C) 2014 Elsevier B.V. All rights reserved.

\section{Introduction}

Urban expansion has been one of the leading types of land use change today (Güneralp and Seto, 2013). Due to the long lasting impact upon habitat loss and fragmentation, urbanization often induce great local extinction of natives and has been identified as a major threat to biodiversity (Czech et al., 2000; McKinney, 2002). Furthermore, for urbanization promotes the expansion of exotic and synanthropic species, and induces extinction of some rare natives, it has been a major cause of biotic homogenization, i.e.

\footnotetext{
* Corresponding authors at: Key Laboratory of Coastal Environmental Processes and Ecological Remediation, Yantai Institute of Coastal Zone Research, Chinese Academy of Sciences, Yantai, Shandong 264003, PR China. Tel.: +86 535 2109113; fax: +865352109000.

E-mail addresses: jbyu@yic.ac.cn (J.-B. Yu), shaohongbochu@126.com (H.-B. Shao)
}

the process that disparate locales becoming more similar in species composition over time (McKinney, 2006; Schwartz et al., 2006; Olden, 2006). For biotic homogenization could impair biodiversity form ecological and evolutionary process and even impact economy from human dimension (Olden et al., 2005; Olden, 2006), it has become an important dimension of the biodiversity crisis (Rooney et al., 2007). Simultaneously, urban areas often appear to be the hotspot of vascular plants and even harbor many rare or endangered species owing to the high habitat heterogeneity, vast number of introduced species and the presence of abundant dispersal vectors (McKinney, 2002; Kühn et al., 2004; Kowarik, 2011). With increasing urbanization, the importance of urban areas for biodiversity conservation constantly grows (Miller and Hobbs, 2002; Kowarik, 2011). To preserve urban biodiversity and restore urban green ecosystem, as well as to cope with the exacerbating problem of biotic homogenization, many countermeasures have been proposed (Miyawaki, 1998; Alvey, 2006; Yu et al., 2012), among which constructing urban forest and improving urban green space are 


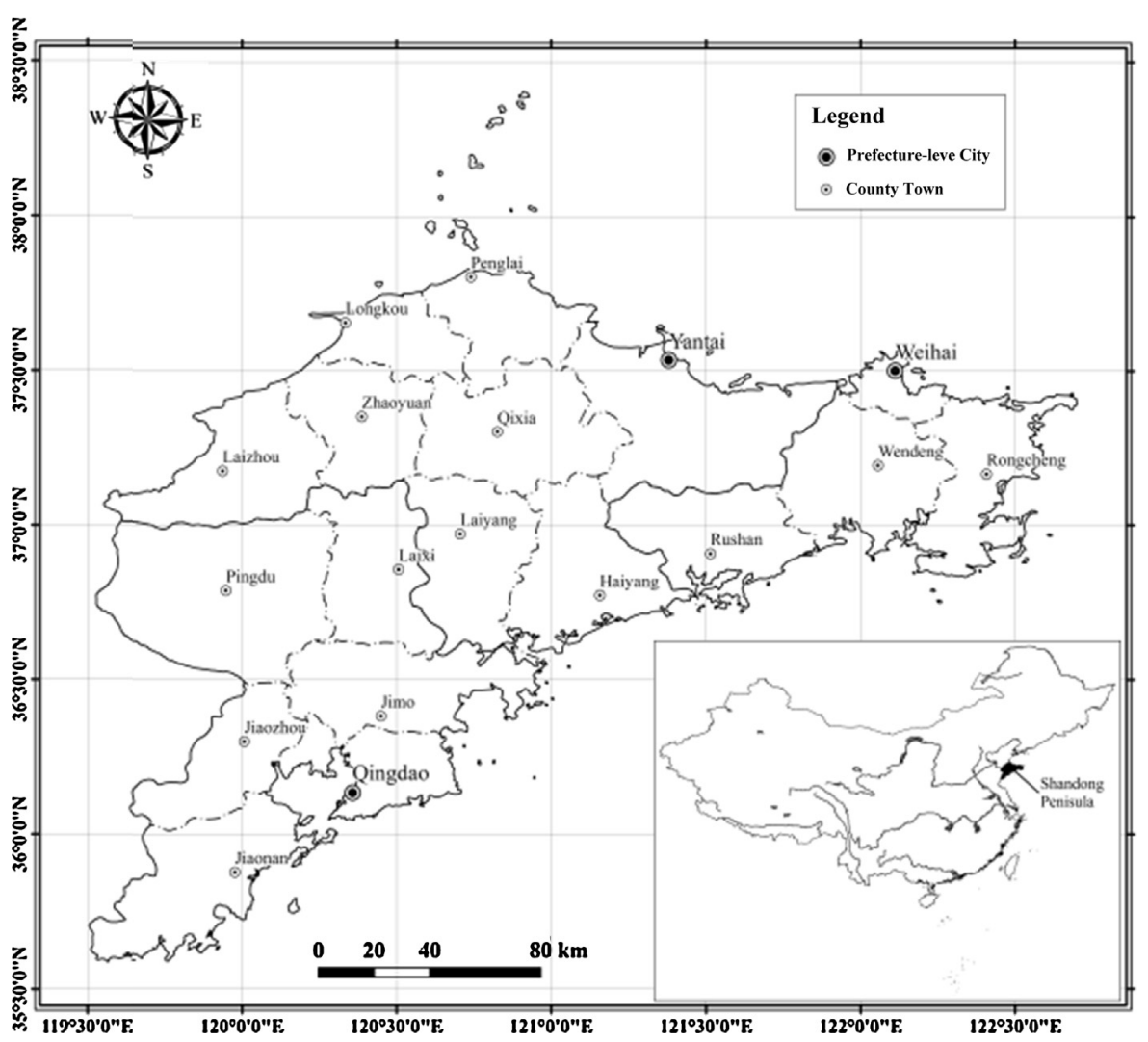

Fig. 1. Location of the investigated 15 towns in Shandong Penisula, China.

most important and fundamental. This point is adopted by many governments and put into practice.

China has experienced a rapid urbanization in the last two decades, with urban expansion much faster in larger cities at national scale (Wang et al., 2012). In recent years, however, many small cities or towns have sprawled with an accelerating rate higher than big cities (Sun et al., 2012). For environment protection and beautification, local governments invest much in urban greening and urban flora construction. However, for majority of new expanded urban areas was transformed from cultivated lands (Sun et al., 2012), most urban flora in the built-up area was almost totally man-made. How such kind of urban floras contribute to local and regional diversity is seldom quantitatively tested. So far, most studies relevant to urban biodiversity in China were conducted in single big cities (e.g. Wang et al., 2006; Zhao et al., 2006; Wang et al., 2007; Zhao et al., 2010); seldom researches were performed in small cities, or compared the urban flora composition among a series of cities. Considering the limited land resources nearby large cities, future urban expansion in China may more happen at small cities or county towns (Wang et al., 2012; Sun et al., 2012). It is therefore essential to concern the biodiversity and conservation efforts in these regions.

In this study, we selected 15 fast urbanizing county towns to explore the effects of urban forest construction on local and regional biodiversity. These county towns belong to Shandong Peninsula Urban Agglomeration, the fourth biggest Urban Agglomeration in China, and have expanded their built-up area of 2.50 -folds in average in ten years' time span from 2000 to 2010. Simultaneously, the local governments invest much in urban greening. As a consequence, the urban green area of the 15 county towns enlarged 3.03-folds in mean, which increased faster than built-up area. The mean urban green area of the 15 county towns has increased to $41.6 \%$, with the per capita public green area of
$15 \mathrm{~m}^{2}$. Due to the improvement in urban greening, majority of these county towns has been listed as National Garden City, National Environmental Protection Model City, National Excellent Tourism City or National Ecological County. It seemed that the construction of the urban forest in this region is rather sound and the biodiversity conservation in these county towns are well done. However, it was just an assumed conclusion without quantitative tests. What are the compositional characteristics of these man-made urban floras? Does fast-growing urbanization leading to high proportion of exotic species in urban green space? Has the huge investment in urban greening resulted in high local or regional diversity? Does the planting and management practice, especially the introduction of exotic species, lead to biotic homogenization at this narrow scale? These questions are important for further urban greening and biodiversity conservation nevertheless seldom tested quantitatively yet. We, therefore, conducted a comprehensive investigation of the urban flora of these 15 fast urbanizing county towns to evaluate the effectiveness of urban greening on biodiversity preservation and restoration, which is the first report in this aspect along Shandong coastal zone, China. For the purpose of this study, we just investigated the man-made urban flora with the natural or semi-natural habitats not considered.

\section{Materials and methods}

\subsection{Study area}

The 15 county towns we sampled are located in the eastern part of Shandong Peninsular (Fig. 1), in the north temperate monsoon climatic zone while having some characters of marine climate. The mean annual precipitation is $670 \mathrm{~mm}$ and the mean air temperature $12.7^{\circ} \mathrm{C}$. The county towns are distributed densely in the Shandong Peninsular, with the maximum geographical distance being $262 \mathrm{~km}$ 
and minimum being $20 \mathrm{~km}$. In the last two decades, the 15 counties undergone a fast urbanization and have been among the most developed counties in China. The mean area of 15 county towns was $37.3 \mathrm{~km}^{2}$ (ranged from 15.3 to 55.0 , s.d. $=10.1$ ) in 2010, which increased 2.50 times compared with 2000 (mean $=15.1$, ranged from 7.0 to 23.1 , s.d. $=4.4$ ). In 2012, 12 of all the 15 towns were listed as the National 100 top counties in terms of competitive power.

\subsection{Data collection}

Investigation was performed from April to October in 2011-2012. To guarantee that the ephemeral plants were documented, each county town was investigated twice in Spring and Autumn, respectively. Mesh point method was applied to design the sampling point. Using the satellite image of Google Earth, the built-up area of each county town was separated into $2 \mathrm{~km} \times 2 \mathrm{~km}$ grids. The intersection points were preliminarily determined as the sampling points, which were some adjusted according to the actual situation when investigated. The green space of four main habitat types, i.e. City Park, residential areas, city square, and roadside, were investigated nearby the designed sampling point. It should note that not all four habitat types were mandatorily investigated at every designed sampling point for there was just one or two habitat types existed under some circumstances. However, to guarantee that the investigation area could represent the green spaces of the built-up area, at least 4 residential areas, 4 roadsides, 1 city park and 1 city square (some county towns just had one city park or city square) were sampled in each county town.

Due to the composition of urban green spaces in built-up areas were influenced significantly by landscape design, the classic sampling method in natural habitat could not meet the need of this study. We therefore using patch-sampling method in the investigation with the sample areas of different habitat types determined referenced to past researches (Sudha and Ravindranath, 2000; Shaltout and E.I-Sheikh, 2002; Zhao et al., 2009). For the city park, city square and residential areas, if the total area is less than or near 1 ha, we sampled all green spaces; if the area was much larger than 1 ha, the investigation area were set as $200 \mathrm{~m} \times 200 \mathrm{~m}$. For the roadsides, we investigated $200 \mathrm{~m}$ at each side. All vascular plant species in the sample area were recorded. For the species which could not confirmed in the field investigation, plant samples were collected, dried, labeled and then determined according to standard herbarium procedures. The pooled species list across all sampled plots in each county town was compiled as the plant species catalog of the urban green spaces. All species were firstly classified as native or exotic by their immigration status (Pysěk et al., 2004), which was consistent with the Flora of China (Wu et al., 1994-2013), Flora of Shandong Province (Chen et al., 1992-1994) and specialized database (Jiang et al., 2011). For native and exotic species, they were further divided respectively into cultivated or wild according to whether they were deliberately planted or not. Six sub-catalogs, i.e. native, exotic, wild native, wild exotic, cultivated native and cultivated exotic, were thereby constructed for analysis.

\subsection{Data analysis}

Composition dissimilarity patterns are originated from two distinct processes, the replacement of species and the loss or gain of species leading to richness difference. Many methods have been proposed for such partition based on pairwise comparison of sites (Baselga, 2010, 2012; Podani and Schmera, 2011; Carvalho et al., 2012). Evaluated their performance on theoretical ground and tested using simulation study and empirical data, the method that decomposition of the Jaccard index, $\beta_{c c}$ into $\beta_{-3}$ and $\beta_{\text {rich }}$ was recommended when the aim of the study is to evaluate the relative roles of replacement and species loss or gain in generating beta diversity pattern (Carvalho et al., 2013). In this study, we adopted this method to evaluate the beta diversity pattern of 105 pairwise towns of 6 plant groups across the 15 towns. The general mathematical partition: $\beta_{\text {broad-sense }}=\beta_{\text {replacement }}+\beta_{\text {richness }}$ shows the overall (broad-sense) dissimilarity is equal to the sum of dissimilarity owing to species replacement and richness difference. The overall dissimilarity is quantified as the Jaccard dissimilarity index,

$\beta_{c c}=\frac{b+c}{a+b+c}$

where $a$ is the number of species common to compared towns and, $b$ and $c$ are the numbers of species unique to each town. The species replacement component, $\beta-3$ is quantified as:

$\beta-3=\frac{2 \min (b, c)}{a+b+c}$, and the richness difference component,

$\beta_{\text {rich }}=\frac{|b-c|}{a+b+c}$.

To evaluate the difference of the dissimilarity of pairwise towns of native/exotic pair, paired $t$ test was conducted in 3 pairs of plant groups respectively, i.e. wild native vs. wild exotic, cultivated native vs. cultivated exotic and total native vs. total exotic. All of the three metrics of dissimilarity, $\beta_{c c}, \beta_{-3}, \beta_{\text {rich }}$ were compared, respectively.

The values of the two components, $\beta_{-3}$ and $\beta_{\text {rich }}$ were compared to reveal which contribute more to the overall dissimilarity between town pairs. To disentangle which component influence more to the variation of overall dissimilarity among different pairwise towns, we performed univariate Mantel tests designating the response matrix as the overall dissimilarity, $\beta_{c c}$, and the predictor matrix as either the species replacement component, $\beta_{-3}$ or as the matrix of richness difference resultant component, $\beta_{\text {rich }}$. We did not consider these two predictor variables within a same statistical model using a partial Mantel test because $\beta_{-3}$ and $\beta_{\text {rich }}$ are additive components of the response $\beta_{c c}$, so conditioning on either predictor in a partial Mantel test would have been nonsensical. This procedure was performed for all 6 plant groups, respectively.

To reveal whether the wild flora between pairwise towns had been homogenized or not due to the introduction of wild exotic species, we compared the $\beta_{c c}, \beta_{-3}$ and $\beta_{\text {rich }}$ values of wild native species with wild species, respectively. Higher dissimilarity values of wild native species than that of wild species mean that expansion of wild exotic species leads to decrease of dissimilarity thus contribute to homogenization, otherwise indicating differentiation (Olden, 2006). The same procedure was repeated to explore the homogenization/differentiation tendency of cultivated flora and total flora between pairwise towns (comparing the $\beta_{c c}, \beta_{-3}$ and $\beta_{\text {rich }}$ of cultivated native species with cultivated species, and native species with total species, respectively).

All these calculations and analysis were performed using the $\mathrm{R}$ statistical software, version 2.15.2 (R Core Team, 2013).

\section{Results}

\subsection{Flora composition}

The urban green spaces of 15 surveyed county towns harbored total 397 plant species, of which 303(76.6\%) are native and 94(23.4\%) are exotic (Table 1). Specific to single town, each town harbor $180 \pm 19$ (mean \pm s.d.) species on average, of which $134 \pm 15$ $(74.5 \% \pm 2.8 \%)$ are native and $46 \pm 7(25.5 \% \pm 3.0 \%)$ are exotic. There are $100 \pm 14(55.5 \% \pm 5.1 \%)$ species belonging to cultivated, of which about $27.5 \% \pm 3.2 \%$ being exotic. Of the average $80 \pm 13$ wild plant in single town, the proportion of exotics decreased to 
Table 1

Species composition of urban green spaces in investigated 15 towns in Shandong Peninsular.

\begin{tabular}{|c|c|c|c|c|c|c|c|}
\hline Town & Total & Native & Exotic & Wild native & Cultivated native & Wild exotic & Cultivated exotic \\
\hline Haiyang & 177 & 137 & 40 & 68 & 69 & 20 & 20 \\
\hline Jimo & 159 & 106 & 53 & 43 & 63 & 19 & 34 \\
\hline Jiaonan & 187 & 133 & 54 & 56 & 77 & 17 & 37 \\
\hline Jiaozhou & 196 & 145 & 51 & 63 & 82 & 16 & 35 \\
\hline Laixi & 207 & 148 & 59 & 66 & 82 & 26 & 33 \\
\hline Laiyang & 183 & 137 & 46 & 61 & 76 & 17 & 29 \\
\hline Laizhou & 146 & 109 & 37 & 47 & 62 & 15 & 22 \\
\hline Longkou & 177 & 130 & 47 & 52 & 78 & 16 & 31 \\
\hline Penglai & 199 & 151 & 48 & 64 & 87 & 16 & 32 \\
\hline Pingdu & 162 & 121 & 41 & 53 & 68 & 19 & 22 \\
\hline Qixia & 145 & 111 & 34 & 55 & 56 & 16 & 18 \\
\hline Rongcheng & 187 & 147 & 40 & 86 & 61 & 18 & 22 \\
\hline Rushan & 191 & 148 & 52 & 79 & 69 & 18 & 25 \\
\hline Wendeng & 206 & 154 & 52 & 76 & 78 & 21 & 31 \\
\hline Zhaoyuan & 182 & 138 & 45 & 61 & 77 & 20 & 24 \\
\hline Total & 397 & 303 & 94 & 153 & 150 & 39 & 55 \\
\hline
\end{tabular}

Table 2

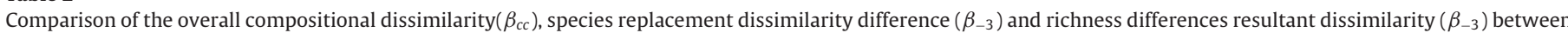
pairwise towns of different plant groups. The differences were tested using paired- $t$ test.

\begin{tabular}{|c|c|c|c|c|c|c|}
\hline Plant groups & $\Delta \beta_{c c}$ mean (s.d.) & $P$ & $\Delta \beta_{-3}$ mean (s.d.) & $P$ & $\Delta \beta_{\text {rich }}$ mean (s.d.) & $P$ \\
\hline Wild native-wild exotic & $0.03(0.10)$ & 0.005 & $-0.01(0.15)$ & 0.525 & $0.04(0.15)$ & 0.010 \\
\hline Cultivated native-cultivated exotic & $0.06(0.11)$ & 0.001 & $0.14(0.11)$ & 0.001 & $-0.08(0.05)$ & 0.001 \\
\hline Native-exotic & $0.04(0.06)$ & 0.000 & $0.08(0.02)$ & 0.001 & $-0.04(0.11)$ & 0.001 \\
\hline
\end{tabular}

$23.1 \% \pm 3.4 \%$. Classified further, of the exotics in each town about $60.3 \pm 6.2 \%$ are deliberately planted (Table 1 ).

\subsection{Composition dissimilarity between town pairs}

Wild exotic has lower pairwise overall dissimilarity $\left(\beta_{c c}\right)$ than wild native, and so does the cultivated exotic vs. cultivated native pair (Table 2). As a result, exotic species also has lower pairwise overall dissimilarity than native species. When comparing the other two dissimilarity metrics, wild exotic species has no difference with wild native species in replacement dissimilarity $\left(\beta_{-3}\right)$, nevertheless its richness difference resultant dissimilarity $\left(\beta_{\text {rich }}\right)$ is higher (Table 2). Cultivated native vs. cultivated exotic pair present different pattern: cultivated exotic species has lower replacement dissimilarity but higher richness difference resultant dissimilarity. The same pattern also presents in the native vs. exotic pair (Table 2).

When measuring the pairwise dissimilarity of 6 plant groups among 15 towns, $\beta_{-3}$ is higher than $\beta_{\text {rich }}$ in overwhelming majority (80-100, i.e. 76-95\%) of 105 pairs in 5 plant groups except cultivated exotic species, indicating that the overall dissimilarity of these plant groups between pairwise towns is mainly contributed by replacement rather than richness difference. As for the cultivated exotic species, $\beta_{-3}$ is higher than $\beta_{\text {rich }}$ in 57 pairs while lower in other 48 pairs, demonstrating the nearly same contribution of species replacement and richness difference. Mantel test results show that in 4 plant groups, including wild exotic, cultivated native, native and exotic, variations of $\beta_{c c}$ among the 105 pairwise comparisons is mainly impacted by $\beta_{-3}$ and little influenced by $\beta_{\text {rich }}(P>0.05)$ (Table 3$)$. Wild native group show opposite pattern: $\beta_{\text {rich }}$ impact the variations of $\beta_{c c}$ significantly while $\beta_{-3}$ present little $(P>0.05)$ influence (Table 3$)$. As for the cultivated exotic plant groups, $\beta_{-3}$ and $\beta_{\text {rich }}$ both significantly influence the variations of $\beta_{c c}$, nevertheless $\beta_{\text {rich }}$ has larger impact (Table 3 ).

\subsection{Biotic homogenization patterns}

In 68(65\%) pairs of all 105 pairwise comparisons wild native species has higher overall dissimilarity $\left(\beta_{c c}\right)$ than wild species, demonstrating the homogenization tendency of wild flora due to the expansion of wild exotic species (Fig. 2a). There are also $81 \%$ (85) pairs of cultivated flora present homogenization tendency owing to the expansion of cultivated exotic species (Fig. 2d). As a result, in 71(68\%) pairwise towns the total flora tends to homogenization (Fig. $2 \mathrm{~g}$ ). As for the other two dissimilarity metrics, most pairs $(81,77 \%)$ of wild flora tend to homogenization for richness difference metric (Fig. 2c), whereas more pairs (66, 63\%) show differentiation trend for species replacement metric (Fig. 2b). Cultivated flora show opposite pattern with wild flora in these two metrics: most pairs $(84,80 \%)$ present homogenization for species replacement metric (Fig. 2e), while more pairs (70,67\%) show differentiation for richness difference metric (Fig. 2f). When the total flora was considered, majority pairs of the other two metrics tend to homogenization (native species has higher $\beta_{-3}$ and $\beta_{\text {rich }}$ than total species in 59 and 56 pairs, respectively, Fig. $2 \mathrm{~h}$ and i). As a consequence, wild flora show homogenization for $\beta_{c c}$ and $\beta_{\text {rich }}$ metric with the mean dissimilarity across 105 pairs decreased by $1.2 \%$ for $\beta_{c c}\left(\overline{\Delta \beta_{c c}}=0.006\right.$, s.d. $\left.=0.011\right)$ and $13.9 \%$ for $\beta_{\text {rich }}\left(\overline{\Delta \beta_{\text {rich }}}=0.023\right.$, s.d. $=0.039)$, and present differentiation for $\beta_{-3}\left(\overline{\Delta \beta_{-3}}=-0.027\right.$, s.d. $=0.039$ ) with the mean dissimilarity increased by $5.3 \%$; cultivated flora was homogenized for $\beta_{c c}$ (decreased by $6.1 \%$ ) and $\beta_{-3}$ metric(decreased by $10.3 \%$ ) and differentiated for $\beta_{\text {rich }}$ metric(increased by $7.6 \%$ ). Merged the wild and cultivated into total flora, the mean dissimilarity of total flora across 105 pairs decreased

Table 3

Contribution of variation of species replacement resultant dissimilarity $\left(\beta_{-3}\right)$ and richness difference resultant dissimilarity $\left(\beta_{\text {rich }}\right)$ to variation of overall dissimilarity $\left(\beta_{c c}\right)$. The correlation coefficients and $P$-values are based on Mantel test (999 times).

\begin{tabular}{lllll}
\hline Plant groups & $\beta_{-3}-\beta_{c c}$ & $P$ & $\beta_{\text {rich }}-\beta_{c c}$ & $P$ \\
\hline Wild native & 0.1087 & 0.215 & 0.5586 & 0.001 \\
Wild exotic & 0.7422 & 0.001 & 0.0205 & 0.525 \\
Cultivated native & 0.4545 & 0.001 & 0.1866 & 0.104 \\
Cultivated exotic & 0.3033 & 0.001 & 0.4352 & 0.001 \\
Native & 0.4456 & 0.002 & 0.1421 & 0.161 \\
Exotic & 0.4716 & 0.001 & 0.2310 & 0.073 \\
\hline
\end{tabular}



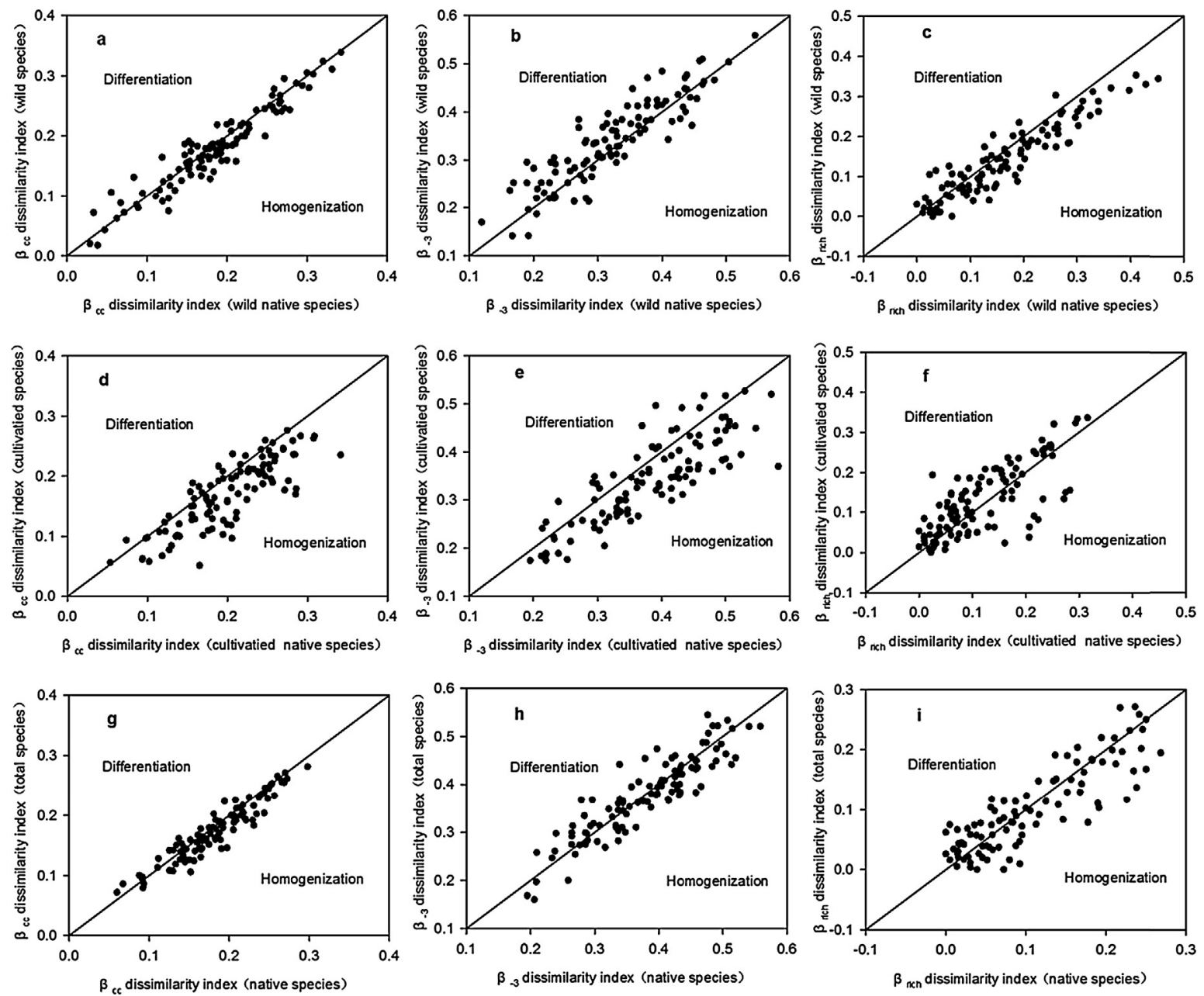

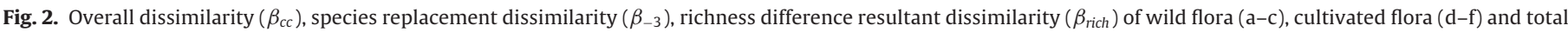

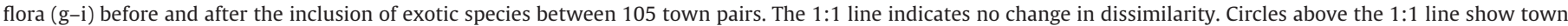
pairs where dissimilarity decreased (homogenization), and circles below the 1:1 line show town pairs where dissimilarity increased (differentiation).

by $1.8 \%$ for $\beta_{c c}, 0.7 \%$ for $\beta_{-3}$ and $5.6 \%$ for $\beta_{\text {rich }}$, indicating homogenization for each metric (Table 4).

\section{Discussions}

Our investigation revealed that the huge investment brought high urban green coverage yet not caused high species diversity. Relative to the abundant vascular plant species (about 2000 species) in this area (Chen et al., 1992-1994), the species diversity of the 15 county towns with 397 species total and average 180 each was rather low. Urban environment may limit the survival of some species through biodiversity filters (Williams et al., 2009); however, such low species diversity also reflected some deficiencies in urban greening and management. Attention more addressed to beautification effect rather than biodiversity conservation led to urban green spaces relative simply structured (Li et al., 2005), which were usually composited with a few frequently used garden plant. Relative limited plant resources that the landscape designer would like to utilize, or they could use with their knowledge, contributed this pattern (Li et al., 2005). This condition reminded us should not only notice the quantity (green coverage area and green coverage rate) but also need to pay more attention to the quality (composition, diversity and ecosystem function) in urban greening.

Another unexpected result is the relative low proportion of exotic species. Exotic species often take high proportion in urban areas due to abundant dispersal factors and their better adaptation to man-made disturbance (Alvey, 2006; Kowarik, 2011). However, the proportion that exotic species holding in the 15 towns we surveyed is rather low compared with other cities. To illustrate, we conducted a comparison with 18 Central European towns for there were seldom researches conducted in county-level flora in China. These 18 towns had a city area ranging from 21 to $53 \mathrm{~km}^{2}$ and population ranging from 13 to 87 thousands, which are analogical with our investigated towns (Pysěk, 1998). However, the proportion

Table 4

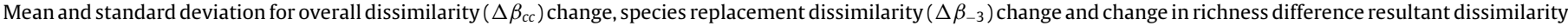
$\left(\Delta \beta_{\text {rich }}\right)$ across 105 pairs of 15 towns.

\begin{tabular}{|c|c|c|c|}
\hline Type & $\Delta \beta_{c c}$ mean (s.d.) & $\Delta \beta_{-3}$ mean (s.d.) & $\Delta \beta_{\text {rich }}$ mean (s.d.) \\
\hline Wild flora & $0.006(0.021)$ & -0.017 (0.039) & $0.023(0.039)$ \\
\hline Cultivated flora & $0.030(0.033)$ & $0.039(0.051)$ & $-0.009(0.059)$ \\
\hline Total flora & $0.009(0.016)$ & $0.003(0.036)$ & $0.006(0.038)$ \\
\hline
\end{tabular}


$(41.4 \% \pm 8.1,31-58 \%)$ of exotic species in these towns is significantly higher than that in the 15 towns $(23.1 \% \pm 3.4 \%, P<0.01)$. City size may influence the presence of exotics (Pysěk, 1993); however, even in the three nearby lager prefecture-level cities, Qingdao, Yantai and Weihai, exotic species also hold an average proportion of $25.8 \% \pm 0.9 \%$ (unpublished data). This pattern may reflect that urban floras also related the overall character of the surrounding flora (StešEvić et al., 2009; Ramage et al., 2013).

However, even exotic species just hold a low proportion, for their overall dissimilarity between towns is lower than native species (Table 2), its expansion has caused the decrease of plant compositional dissimilarity between pairwise towns thus result in homogenization. Both the wild and cultivated flora demonstrates this tendency for the $\boldsymbol{\beta}_{\boldsymbol{c c}}$ (overall dissimilarity) metric thus leading to the same pattern of total flora. Nevertheless, specific to the two distinct processes leading to homogenization, wild and cultivated flora present opposite patterns. This reflects the different impact of urban green practice upon them. Exotic species resource used for cultivation in the region is far poorer than native species (Table 1), which made the selection of them is more common than native species among towns, thus cultivated species has lower replacement rate. From another aspect, the preference of these exotic species may be varied between towns. Some towns are willing to use more exotic species (such as Jiaonan and Jiaozhou) while some other towns (such as Jimo and Qixia) do not, leading to lager richness gradient than cultivated native species. This could be reflected by the higher coefficient of variations (22.1\%) of cultivated exotic species than that of cultivated native species (12.5\%). Coincidently, these towns using more exotic species for cultivation also tend to have more abundant cultivated native species $(r=0.691$, $P<0.01$, Table 1). Therefore, the introduction of the exotic species for cultivation decrease the replacement rate of cultivated flora but increased the richness gradient, thus induce homogenization for $\beta_{-3}$ metric but differentiation for $\beta_{\text {rich }}$ metric. As for the wild species, they are unintentionally introduced into the urban green space. They pass various filters of urban environment and survive for their disturb-adapted characters. The higher species richness difference between towns of wild natives reflect itself more diverse composition than wild exotics in this region (Table 1 ). The species replacement rate of wild native between different town pairs is relative constant $(0.322 \pm 0.087)$, for its variation of pairwise overall dissimilarity is mainly driven by richness difference dissimilarity (Table 3). On the contrary, species replacement component influence the variation of the pairwise overall dissimilarity of wild exotic significantly, demonstrating its higher variation $(0.332 \pm 0.141)$. Therefore, the expansion of wild exotics decreased the richness gradient of wild flora but increased the replacement rate, thus induce homogenization for $\beta_{\text {rich }}$ metric but differentiation for $\beta_{-3}$ metric. For total flora is more influenced by the cultivated in species number (Table 1), it demonstrate the same tendency as cultivated flora (Table 4).

From the viewpoint of urban greening, we need pay more attention to the homogenization tendency of cultivated flora. It is not only due to the cultivated species account for majority of urban flora, but also for they supplying most ecological functions in urban area. From ecological dimension, homogenization of cultivated flora may increase vulnerability to large-scale environmental events and reduce variability among towns in their response to disturbance (Olden, 2006); from human and economic dimension, for cultivated species are the main part to demonstrate landscape effect, its compositional homogenization may present straightly as 'visual homogenization', i.e. making the passengers feel cities more alike; from economic dimension, this would compromise tourism industry because the public will have less interest to visit areas similar to those in closer proximity (Olden et al., 2005). Cultivated flora in the 15 towns have experienced significant homogenization in overall dissimilarity metric and species replacement metric, thus more efforts need to be taken in future urban greening to cope with this problem. Landscape designers need to do thorough examination of regional native plants and their biology and utilize as diverse as possible plant resources in urban greening (Simmons et al., 2007). Some endemic species should to be applied as much as possible, which cannot only embody the character of local flora, but also contribute to build diverse landscapes among different cities. Furthermore, varied landscapes may benefit foster diversity of wild plant, which could in turn alleviate the homogenization tendency of spontaneous flora. Moreover, diverse urban greening models need to be considered. For example, green roofs has been approved a valuable tool to conciliate the greening of cites with ecological conservation and environmental quality improvements (Farrell et al., 2012; Chen, 2013; Madre et al., 2013), yet this type of urban greening is seldom utilized in the study area. Some remnant natural plant, such as stonewall trees, also need to be protected for enriching urban biodiversity (Jim, 2013). However, to achieve this goal, more education may need to improve the public acceptance of native species, especially for those ecological valuable but not so good-looking natives (Breuste, 2004).

\section{Conclusions}

In summary, our study revealed some deficiencies in urban green space construction in the study area. Huge investment in urban greening contributed to high green coverage however not resulted in high biodiversity. Paying more attention to beautification in decision-making weakened the ecological function of urban green spaces in biodiversity conservation and has caused biotic homogenization. Unfortunately, the problem is not any individual case but prevalent in urban forest construction in China ( $\mathrm{Li}$ et al., 2005). Considering the fast-growing urbanization in China, the problem would be exacerbated with no improvement in current construction model of urban greening. Biodiversity conservation should be more considered in future urban greening, and public participation need to be more encouraged and strengthened (Alvey, 2006; Miller et al., 2008). Fortunately, with the increasing civic consciousness in recent years, more and more people began to have positive attitudes and strong willingness toward participation in urban China (Shan, 2012), which will benefit the decision-making and construction in urban greening. Professional advice from conservation biologists and ecologists maybe more important, and these advice should be based on concrete investigation and research. In China, more research has been conducted in relative big cities nevertheless seldom done in small cities and towns. Thus, more studies need to develop at this scale to resolve specific problem. In addition, though biotic homogenization has been a hotspot in biodiversity research (Olden, 2006; Petesse and Petrere Jr, 2012), research on this topic is rather rare in China. Deficiency of open, reliable databases is an important reason, thus the establishment of such database is emergently needed to foster biotic homogenization research in China. Our research, especially the species composition data, could contribute to this work and supply useful reference to such studies in other area in China.

\section{Acknowledgments}

This study was jointly funded by Natural Science Foundation of China (30900213,31370474), Project of National Science \&Technology Pillar Program in“12th Five Year" period (2011BAC02B01), the CAS/SAFEA International Partnership Program for Creative Research Teams, Yantai Science \& Technology Development Project 
(2010161; 2011016), Yantai Double-hundred High-end Talent Plan (XY-003-02), the Science \& Technology Development Plan of Shandong Province (010GSF10208) and 135 Development Plan of YIC-CAS. We also would like to thank Gao Meng, Hou Xiaokai, Zheng Lei for their help in data collection and analysis.

\section{References}

Alvey, A.A., 2006. Promoting and preserving biodiversity in the urban forest. Urban For. Urban Green. 5, 195-201.

Baselga, A., 2010. Partitioning the turnover and nestedness components of beta diversity. Global Ecol. Biogeogr. 19, 134-143.

Baselga, A., 2012. The relationship between species replacement dissimilarity derived from nestedness and nestedness. Global Ecol. Biogeogr. 21 1223-1232.

Breuste, J.H., 2004. Decision making, planning and design for the conservation of indigenous vegetation within urban development. Landscape Urban Plan. 68, 439-452.

Carvalho, C.G., Cardoso, P., Borges, P.A.V., Schmera, D., Podani, J., 2013. Measuring fractions of beta diversity and their relationships to nestedness: a theoretical and empirical comparison of novel approaches. Oikos 122, 825-834.

Carvalho, J.C., Cardoso, P., Gomes, P., 2012. Determining the relative roles of species replacement and species richness differences in generating beta-diversity patterns. Global Ecol. Biogeogr. 21, 760-771.

Chen, C.F., 2013. Performance evaluation and development strategies for green roofs in Taiwan: a review. Ecol. Eng. 52, 51-58.

Chen, H.B., Zheng, Y.J., Li, F.Z., 1992-1994. Flora of Shandong Province. Qingdao Press, Qingdao.

Czech, B., Krausman, P.R., Devers, P.K., 2000. Economic associations among causes of species endangerment in the United States. Bioscience 50, 593-601.

Farrell, C., Mitchell, R.E., Szota, C., Rayner, J.P., Willams, N.S.G., 2012. Green roofs for hot and dry climates: interacting effects of plant water use, succulence and substrate. Ecol. Eng. 49, 270-276.

Güneralp, B., Seto, K.C., 2013. Futures of global urban expansion, uncertainties and implications for biodiversity conservation. Environ. Res. Lett. 8, 014025.

Jiang, H., Qian, F., Li, J.T., Shi, S., Li, S.P., Liao, B.W., Shu, W.S., 2011. Naturalization of exotic plants in China. Biodivers. Conserv. 20, 1545-1556.

Jim, C.Y., 2013. Drivers for colonization and sustainable management of treedominated stonewall ecosystems. Ecol. Eng. 57, 324-335.

Kowarik, I., 2011. Novel urban ecosystems biodiversity, and conservation. Environ. Pollut. 159, 1974-1983.

Kühn, I., Brandl, R., Klotz, S., 2004. The flora of German cities is naturally species rich. Evolutionary Ecol. Res. 6, 749-764

Li, F., Wang, R.S., Liu, X.S., Zhang, X.L., 2005. Urban forest in China: development patterns, influencing factors and research prospects. Int. J. Sustain. Dev. World Ecol. 12, 197-204.

Madre, F., Vergnes, A., Machon, N., Clergeau, P., 2013. A comparison of 3 types of green roof as habitats for arthropods. Ecol. Eng. 57, 109-117.

Miyawaki, A., 1998. Restoration of urban green environments based on the theories of vegetation ecology. Ecol. Eng. 11, 157-165.

McKinney, M.L., 2006. Urbanization as a major cause of biotic homogenization. Biol. Conserv. 127, 247-260.

McKinney, M.L., 2002. Urbanization, biodiversity, and conservation. Bioscience 52, 883-890.

Miller, J.R., Groom, M., Hess, G.R., Steelman, T., Stokes, D.L., Thompson, J., Bowman, T., Fricke, L., King, B., Marquardt, R., 2008. Biodiversity conservation in local planning. Conserv. Biol. 23 (1), 53-63.

Miller, J.R., Hobbs, R.J., 2002. Conservation where people live and work. Conserv. Biol. 16, 330-337.

Olden, J.D., Douglas, M.E., Douglas, M.D., 2005. The human dimensions of biotic homogenization. Conserv. Biol. 19, 2036-2038.
Olden, J.D., 2006. Biotic homogenization: a new research agenda for conservation biogeography. J. Biogeogr. 33, 2027-2039.

Petesse, M.L., Petrere Jr., M., 2012. Tendency towards homogenization in fish assemblages in the cascade reservoir system of the Tiete river basin. Brazil. Ecol. Eng. 48, 109-116.

Podani, J., Schmera, D., 2011. A new conceptual and methodological framework for exploring and explaining pattern in presence - absence data. Oikos 120, 1625-1638.

Pysěk, P., Richardson, D.M., Rejmánek, M., Webster, G.L., Williamson, M., Kirschner, J., 2004. Exotic plants in checklists and floras: towards better communication between taxonomists and ecologists. Taxon 53, 131-143.

Pysěk, P., 1993. Factors affecting the diversity of flora and vegetation in central European settlements. Vegetation 106, 89-100

Pysěk, P., 1998. Exotic and native species in Central European urban floras: a quantitative comparison. J. Biogeogr. 25, 155-163.

$\mathrm{R}$ Core Team, 2013. R: A Language and Environment for Statistical Computing. R Foundation for Statistical Computing, Vienna, Austria http://www.R-project.org/

Ramage, B.S., Roman, L.A., Dukes, J.S., 2013. Relationships between urban tree communities and the biomes in which they reside. Appl. Veg. Sci. 16, 8-20.

Rooney, T.P., Olden, J.D., Leach, M.K., Rogers, D.A., 2007. Biotic homogenization and conservation prioritization. Biol. Conserv. 134, 447-450.

Schwartz, M.W., Thorne, J.H., Viers, J.H., 2006. Biotic homogenization of the California flora in urban and urbanizing regions. Biol. Conserv. 127, 282-291.

Shaltout, K.H., E.I-Sheikh, M.A., 2002. Vegetation of the urban habitats in the Nile Delta Region. Egypt Urban Ecosyst. 6, 205-222.

Shan, X.Z., 2012. Attitude and willingness toward participation in decision-making of urban greenspaces in China. Urban For. Urban Green. 11, 211-217.

Simmons, M.T., Venhaus, H.C., Windhager, S., 2007. Exploiting the attributes of regional ecosystems for landscape design. The role of ecological restoration in ecological engineering. Ecol. Eng. 30, 201-205.

StešEvić, D., Jovanović, S., šćepanović, S., 2009. Flora of the city of Podgorica, Montenegro - chronologic structure and comparison with the floras of Rome, Patras, and Salonika. Arch. Biol. Sci. 61 (2), 307-315.

Sudha, P., Ravindranath, N.H., 2000. A study of Bangalore urban forest. Landscape Urban Plan. 47, 47-63.

Sun, P.J., Xiu, C.L., Wang, Q., Ding, S.B., 2012. Study on the Non-conformity of urban spatial expansion in China. Prog. Geogr. 31 (8), 1032-1041.

Wang, Y.G., Zhang, Q.H., Zhang, F., 2006. Effects of the Fenhe river reconstruction project on wild vascular plants in urban Taiyuan. China Ecol. Eng. 28, 1174-1180.

Wang, G.M., Jiang, G.M., Zhou, Y.L., Liu, Q.R., Ji, Y.S., Wang, S.X., Chen, S.B., Liu, H., 2007. Biodiversity conservation in a fast-growing metropolitan area in China: a case study of plant diversity in Beijing. Biodiv. Conserv. 16, 4025-4038.

Wang, L., Li, C.C., Ying, Q., Cheng, X., Wang, X.Y., Li, X.Y., Hu, L.Y., Liang, L., Yu, L., Huang, H.B., Peng, G., 2012. China's urban expansion from 1990 to 2010 determined with satellite remote sensing. China Sci. Bull. 57, 2802-2812.

Williams, N.S.G., Schwartz, M.W., Vesk, P.A., McCarthy, M.A., Amy, K., Hahs, A.H., Clemants, S.E., Corlett, R.T., Duncan, R.P., Norton, B.A., Thompson, K., McDonnell, M.J., 2009. A conceptual framework for predicting the effects of urban environments on floras. J. Ecol. 97, 4-9.

Wu, Z.Y., Raven,.P.H., Hong, D.Y., 1994-2013. Flora of China. Science Press \& Missouri Botanical Garden, Beijing, China and St. Louis, USA.

Yu, D.Y., Xun, B., Shi, P.J., Shao, H.B., Liu, Y.P., 2012. Ecological restoration planning based on connectivity in an urban area. Ecol. Eng. 46, 24-33.

Zhao, S.Q., Da, L.J., Tang, Z.Y., Fang, H.J., Song, K., Fang, J.Y., 2006. Ecological consequences of rapid urban expansion: Shanghai, China. Front. Ecol. Environ. 4 $341-346$.

Zhao, J.J., Ouyang, Z.Z., Zheng, H., Xu, W.H., Wang, X.K., Ni, Y.M., 2009. Proposed procedure in designing and planning stratified random selection investigation of urban vegetation. China J. Ecol. 28 (7), 1430-1436.

Zhao, J.J., Ouyang, Z.Z., Zheng, H., Zhou, W.Q., Wang, X.K., Xu, W.H., Ni, Y.H., 2010. Plant species composition in green spaces within the built-up areas of Beijing. China Plant Ecol. 209, 189-204. 